\title{
A Study of the Optimal Conditions for the Development of Preferred Oriented Platinum Surfaces by Means of Fast Square Wave Potential
}

\section{Perturbations}

\author{
W. E. Triaca, T. Kessler, J. C. Canullo, and A. J. Arvia* \\ Instituto de Investigaciones Fisicoquimicas Teóricas y Aplicadas, Casilla de Correo 16, Sucursal 4, 1900 La Plata, \\ Argentina
}

\section{ABSTRACT}

Changes in the voltammetric response of polycrystalline platinum in the direction expected for preferred oriented surface electrodes are achieved after applying a fast repetitive square wave potential signal covering the potential range of $\mathrm{H}$ - and O-electroadsorption/electrodesorption. The influence of the characteristics of the square wave potential signal on the voltammetric response of the modified platinum surfaces is systematically studied to establish the optimal conditions for obtaining surface structures with determined preferred orientations.

Recently, it was found that changes in the voltammetric response of polycrystalline platinum electrodes in the direction expected for preferred oriented surface electrodes can be achieved by using a fast repetitive square wave potential signal (RSWPS) within the potential range of $\mathrm{H}$ - and O-electroadsorption/electrodesorption in acid solution (1). Similar results were earlier obtained by applying a fast triangular potential signal to a polycrystalline platinum electrode in acid electrolyte at room temperature $(2,3)$. After applying the fast potential perturbation the electrode surface modifications were voltammetrically followed at a low potential sweep rate in the $\mathrm{H}$ - and $\mathrm{O}$-electroadsorption/electrodesorption potential range by using an acid electrolyte. These changes in the electrode surface can also be seen through SEM for a relatively low magnification factor (4). The change from the initial polycrystalline platinum surface to the preferred oriented surface is independent of the shape of the periodic potential perturbation, but it is extremely sensitive to its frequency and potential limits $(1,2,5)$. Thus, depending on the preset parameters of the potential perturbation either the platinum (100) preferred oriented surface or the platinum (111) preferred oriented surface are obtained (1-5).

In the present work the influence of the RSWPS characteristics on the voltammetric response at low potential sweep rate of the resulting platinum surfaces is systematically studied to establish the optimal conditions for obtaining surface structures with a determined preferred orientation.

\section{Experimental}

Runs were made in $1 \mathrm{M} \mathrm{H}_{2} \mathrm{SO}_{4}$ at $25^{\circ} \mathrm{C}$ with commercially available polycrystalline platinum wire shaped working electrodes of ca. $0.10 \mathrm{~cm}^{2}$ geometric area. Previous to each experiment the working electrode was electropolished with ac $(50 \mathrm{~Hz} ; 10-15 \mathrm{~V})$ in a slightly acid (HCl) saturated $\mathrm{CaCl}_{2}$ solution. Later, the electrode was repeatedly rinsed with triply distilled water and kept in water for $1 \mathrm{~h}$ before use. The potential of the working electrode was measured against a RHE in the acid electrolyte. A large area platinum counterelectrode (ca. 50 $\mathrm{cm}^{2}$ ) concentrically surrounding the working electrode was used. The electrochemical cell and the instrumentation have been described elsewhere $(1,5)$. The distortion of the RSWPS, which was due to the proper risetime of the electrochemical setup, was less than $5 \%$ at frequencies lower than $6 \mathrm{kHz}$.

After the pretreatment, the working electrode was subjected to the RSWPS between lower $\left(E_{1}\right)$ and upper $\left(E_{\mathrm{u}}\right)$ potential limits at a certain frequency $(f)$ during a preset time $(t)$. The duration of each potential step, $\tau_{1}$ and $\tau_{u}$, respectively, was adjusted at convenience. Most of the results reported in this paper correspond to $\tau_{1}=\tau_{\mathrm{u}}$ except where otherwise stated. After the RSWPS treatment, vol-

*Electrochemical Society Active Member. tammograms were run either in the $0.05-0.60 \mathrm{~V}$ or in the $0.05-1.50 \mathrm{~V}$ range at $0.1 \mathrm{~V} / \mathrm{s}$.

\section{Results}

Development of the (100) preferred crystal orientation.-When an electropolished polycrystalline platinum electrode in $1 \mathrm{M} \mathrm{H}_{2} \mathrm{SO}_{4}$ at $25^{\circ} \mathrm{C}$ is subjected to a constant amplitude RSWPS at $4 \mathrm{kHz}$ during $5 \mathrm{~min}$, the voltammogram run afterwards at $0.1 \mathrm{~V} / \mathrm{s}$ between 0.05 and $0.60 \mathrm{~V}$ in the same electrolyte depends on the location of $E_{1}$ and $E_{u}$ (Fig. 1) In any case, clear differences are seen between the voltammograms run before and after the RSWPS treatment. Thus, for the particular set of perturbation conditions indicated in Fig. 1, the heights of the weakly adsorbed $\mathrm{H}$-adatom current peaks decrease, those corresponding to the strongly adsorbed $\mathrm{H}$-adatom current peaks simultaneously increase, and a pair of reversible conjugated current peaks located at ca. $0.34 \mathrm{~V}$ is noticed. The greatest voltammetric difference between the treated platinum surface and the initial polycrystalline platinum surface corresponds to $E_{1}=0.25 \mathrm{~V}$ and $E_{\mathrm{u}}=$ $1.25 \mathrm{~V}$ (Fig. 1b), approaching the voltammetric response assigned to the platinum (100) single crystal surface (6-14).

For a constant set of potential perturbation conditions, the influence of $E_{u}$ on the development of the (100) preferred orientation is determined (Fig. 2). For this purpose, the ratio of the strongly adsorbed $\mathrm{H}$-electrodesorption current peak height $\left(h_{2}\right)$ to the weakly adsorbed $\mathrm{H}$-electrodesorption current peak height $\left(h_{1}\right)$ is taken as an arbitrary measure of the degree of development of the (100) preferred orientation. Thus, for $0.20 \mathrm{~V} \leq E_{1} \leq 0.40 \mathrm{~V}, f$ $=4 \mathrm{kHz}$ and $t=5 \mathrm{~min}, E_{\mathrm{u}}$ must be within the $1.10-1.40 \mathrm{~V}$ range for producing a surface structure whose voltammogram at $0.1 \mathrm{~V} / \mathrm{s}$ approaches that of the platinum (100) single crystal surface. At $E_{\text {u }}$ values either lower than

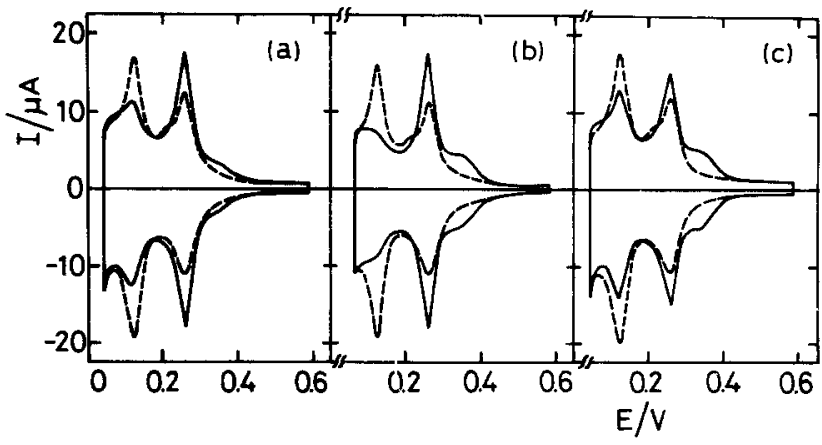

Fig. 1. Voltammograms (third cycle) run at $0.1 \mathrm{~V} / \mathrm{s}$ in $1 \mathrm{M} \mathrm{H}_{2} \mathrm{SO}_{4}$ at $25^{\circ} \mathrm{C}$. (—): (a) After 5 min RSWPS ot $4 \mathrm{kHz}$ between 0.30 and $1.30 \mathrm{~V}$; (b) after $5 \mathrm{~min}$ RSWPS at $4 \mathrm{kHz}$ between 0.25 and $1.25 \mathrm{~V}$; (c) after $5 \mathrm{~min}$ RSWPS at $4 \mathrm{kHz}$ between 0.20 and $1.10 \mathrm{~V}$. (- . -) Untreated electropolished polycrystalline platinum electrode. 


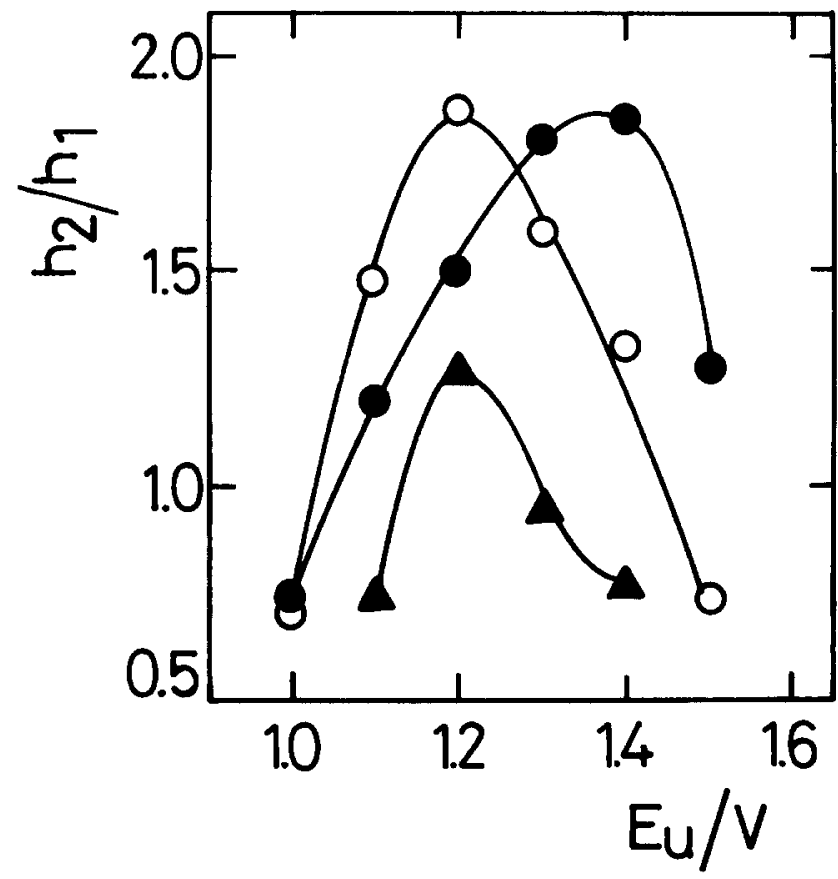

Fig. 2. Dependence of $h_{2} / h_{1}$ on $E_{\mathrm{u}}$ for different $E_{1}:(O) E_{1}=0.20 \mathrm{~V}$; (O) $E_{1}=0.30 \mathrm{~V} ;(\Delta) E_{1}=0.40 \mathrm{~V} ; f=4 \mathrm{kHz} ; t=5 \mathrm{~min}$.

$1.10 \mathrm{~V}$ or higher than $1.40 \mathrm{~V}$ only small changes in the height ratio of the H-electroadsorption/electrodesorption current peaks are observed.

The efficiency for the development of the (100) preferred crystal orientation, $H(100)$, can be arbitrarily expressed as follows

$$
H(100)=\frac{\left(h_{2} / h_{1}\right)_{\mathrm{pos}}-\left(h_{2} / h_{1}\right)_{\mathrm{pc}}}{\left(h_{\mathrm{z}} / h_{1}\right)_{\mathrm{pc}}}
$$

where pos and pc denote the preferred oriented surface and the polycrystalline electrode, respectively. For electropolished polycrystalline platinum electrodes an average $h_{2} / h_{1}$ ratio equal to 0.7 is taken as reference value.

On the other hand, for $E_{\mathrm{u}}=1.20$ or $1.40 \mathrm{~V}, f=4 \mathrm{kHz}$, and $t=5 \mathrm{~min}$, the useful $E_{1}$ potential range for obtaining the (100) preferred orientation is comprised between 0 and

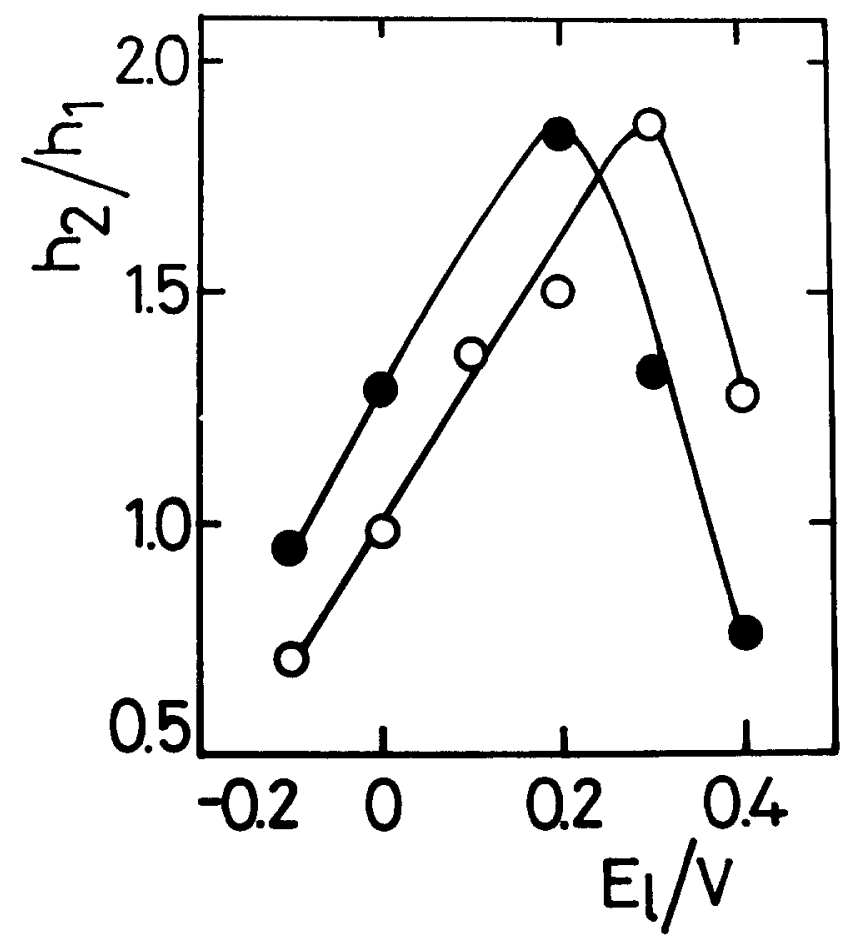

Fig. 3. Dependence of $h_{2} / h_{1}$ on $E_{\mathrm{l}}$ for different $E_{\mathrm{u} i}(O) E_{\mathrm{u}}=1.20 \mathrm{~V}$; (O) $E_{\mathrm{u}}=1.40 \mathrm{~V} ; f=4 \mathrm{kHz} ; t=5 \mathrm{~min}$.

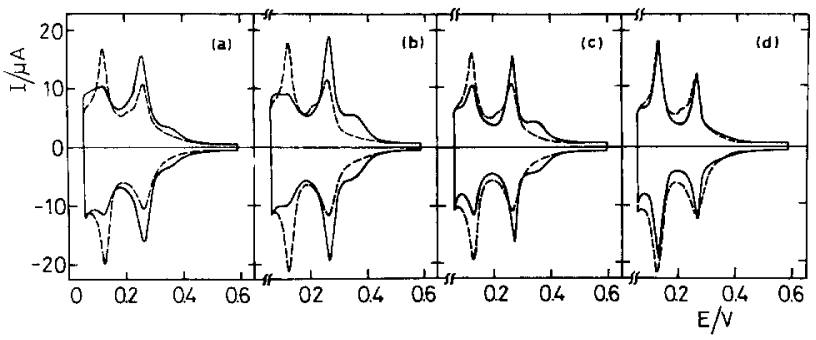

Fig. 4. Voltammograms (third cycle) run at $0.1 \mathrm{~V} / \mathrm{s}$ in $1 \mathrm{M} \mathrm{H}_{2} \mathrm{SO}_{4}$ at $25^{\circ} \mathrm{C}$ after $5 \mathrm{~min}$ RSWPS $\left(E_{1}=0.25 \mathrm{~V} ; E_{u}=1.25 \mathrm{~V}\right)$ at different $f$. (—_): (a) $f=0.5 \mathrm{kHz}$; (b) $f=3 \mathrm{kHz}$; (c) $f=12 \mathrm{kHz}$ (d) $f=20$ kHz. (- - ) Untreated electropolished polycrystalline electrode.

$0.40 \mathrm{~V}$ (Fig. 3). At $E_{1}$ values either higher than 0.40 or lower than $0 \mathrm{~V}$, the development of the (100) preferred orientation is no longer observed.

Under constant $E_{1}, E_{\mathrm{u}}$, and $t\left(E_{1}=0.25 \mathrm{~V}, E_{\mathrm{u}}=1.25 \mathrm{~V}\right.$, $t=5 \mathrm{~min}$ ) the influence of the frequency on the voltammetric response of the resulting surfaces is also studied (Fig 4). The maximum efficiency for developing surfaces with a (100) preferred orientation is found at 2-6 $\mathrm{kHz}$ (Fig. 5). Furthermore, the preferred orientation occurs only beyond a threshold frequency close to ca. 0.5 $\mathrm{kHz}$.

It is interesting to notice that the optimal $E_{1}$ and $E_{0}$ values are practically independent of $f$ for values less than $8 \mathrm{kHz}$. At $f$ larger than $8 \mathrm{kHz}$, the decrease in the efficiency for developing the (100) preferred orientation is accompanied by the increase in the sharpness of the two main pairs of current peaks related to the $\mathrm{H}$-electroadsorption/electrodesorption processes. This suggests that although no preferred orientation is practically achieved at values of $f$ as large as $20 \mathrm{kHz}$ (Fig. 4), the remarkable sharpness of the current peaks can be related to a decrease in the heterogeneity of the electrode surface, as recently reported for the case of platinized platinum electrodes in acid electrolytes (15). On the other hand, as $f$ increases beyond $8 \mathrm{kHz}$ the RSWPS approaches a periodic signal of trapezoidal shape. Hence, to optimize the development of the (100) preferred orientation, for instance, at $f=20 \mathrm{kHz}$, it seems more realistic to set $E_{1}$ and $E_{\mathrm{u}}$ approaching those corresponding to a fast triangular potential signal, namely, $E_{1}=0.10 \mathrm{~V}$ and $E_{\mathrm{u}}$ $=1.50 \mathrm{~V}(3,5)$.

The influence of the duration, $t$, of the RSWPS treatment on the $h_{2} / h_{1}$ ratio, for the optimal conditions for developing the $(100)$ preferred orientation, is depicted in Fig. 6. The $h_{2} / h_{1}$ ratio tends to a limiting value for $t$ larger than $60 \mathrm{~min}$. In this case, after $4 \mathrm{~h}$ of RSWPS treatment, the voltammetric response at $0.1 \mathrm{~V} / \mathrm{s}$ of the resulting surface (Fig. 7), is very close to that reported for platinum (100) single crystal surfaces in $0.5 \mathrm{M} \mathrm{H}_{2} \mathrm{SO}_{4}(12,13)$. Furthermore, as has already been observed for the repetitive voltammetric response of platinum (100) single crystal surfaces, covering the O-electroadsorption potential range $(12,13,16)$, the platinum $(100)$ preferred oriented surface also shows during cycling between 0.05 and $1.50 \mathrm{~V}$ the decrease in height of the main reversible current peaks of H-electroadsorption/electrodesorption and the disappearance of the reversibility of the minor redox

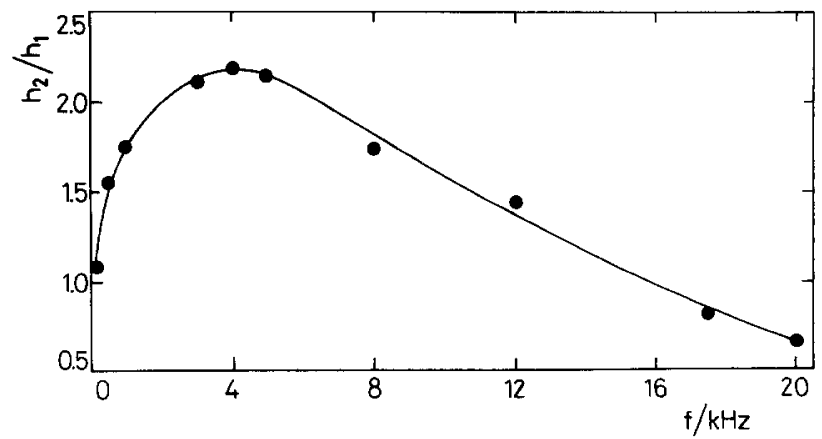

Fig. 5. Dependence of $h_{2} / h_{1}$ on $f . E_{1}=0.25 V ; E_{\mathrm{u}}=1.25 \mathrm{~V} ; t=5 \mathrm{~min}$ 


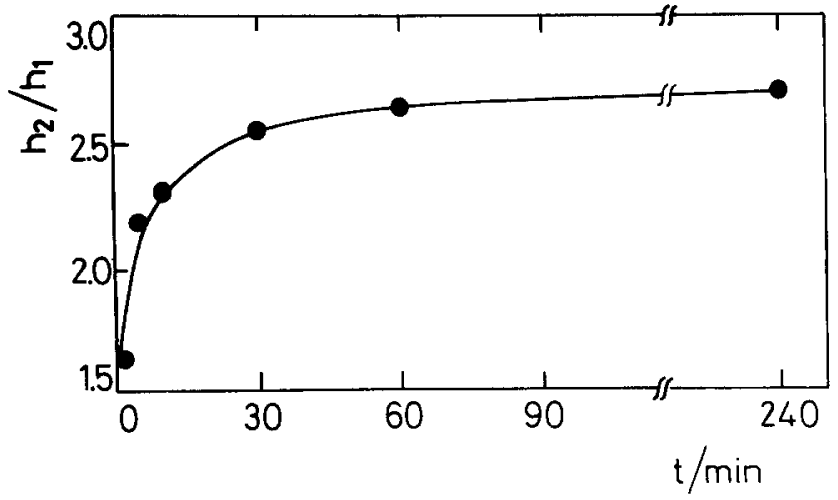

Fig. 6. Dependence of $h_{2} / h_{1}$ on $t . E_{1}=0.25 V ; E_{\mathrm{u}}=1.25 \mathrm{~V} ; f=4 \mathrm{kHz}$

system at ca. $0.34 \mathrm{~V}$ (Fig. 7). Values of $h_{2} / h_{1}$, including double layer charging correction, and $H(100)$ derived from voltammograms run at low potential sweep rate for different treated platinum electrodes, including those derived for platinum (100) single crystals surfaces, are assembled in Table I.

Analysis of the solution in contact with the platinum electrode subjected to the RSWPS under the optimal conditions referred to above (17) shows that the net amount of dissolved ionic platinum per cycle per unit electrode area is about three orders of magnitude lower than that reported in the literature for polycrystalline platinum electrodes cycled at $0.04 \mathrm{~V} / \mathrm{s}$ between 0.40 and $1.50 \mathrm{~V}(18)$.

At constant $E_{1}, E_{u}, f$, and $t$, the development of the (100) preferred orientation depends on the symmetry of the RSWPS, i.e., on both $\tau_{1}$ and $\tau_{\mathrm{u}}$. Thus, for $E_{1}=0.25 \mathrm{~V}, E_{\mathrm{u}}=$ $1.25 \mathrm{~V}, f=4 \mathrm{kHz}$, and $t=5 \mathrm{~min}$, the maximum efficiency of the RSWPS treatment is reached at $0.3 \leq r=\tau_{u} / \tau_{1} \leq 3$ (Fig. 8)

Runs made with a sinusoidal potential signal at $E_{1}$ and $E_{\mathrm{u}}$ values close to those used in the RSWPS treatment $\left(E_{1}\right.$ $=0.20 \mathrm{~V}$ and $E_{\mathrm{u}}=1.40 \mathrm{~V}$ ) and at different $f$, produce preferred orientation effects similar to those described for the RSWPS treatment. For the sinusoidal potential signal treatment both the threshold frequency and the optimal frequency range are similar to those already given for the RSWPS (Fig. 9). These results confirm that the development of the platinum (100) preferred oriented

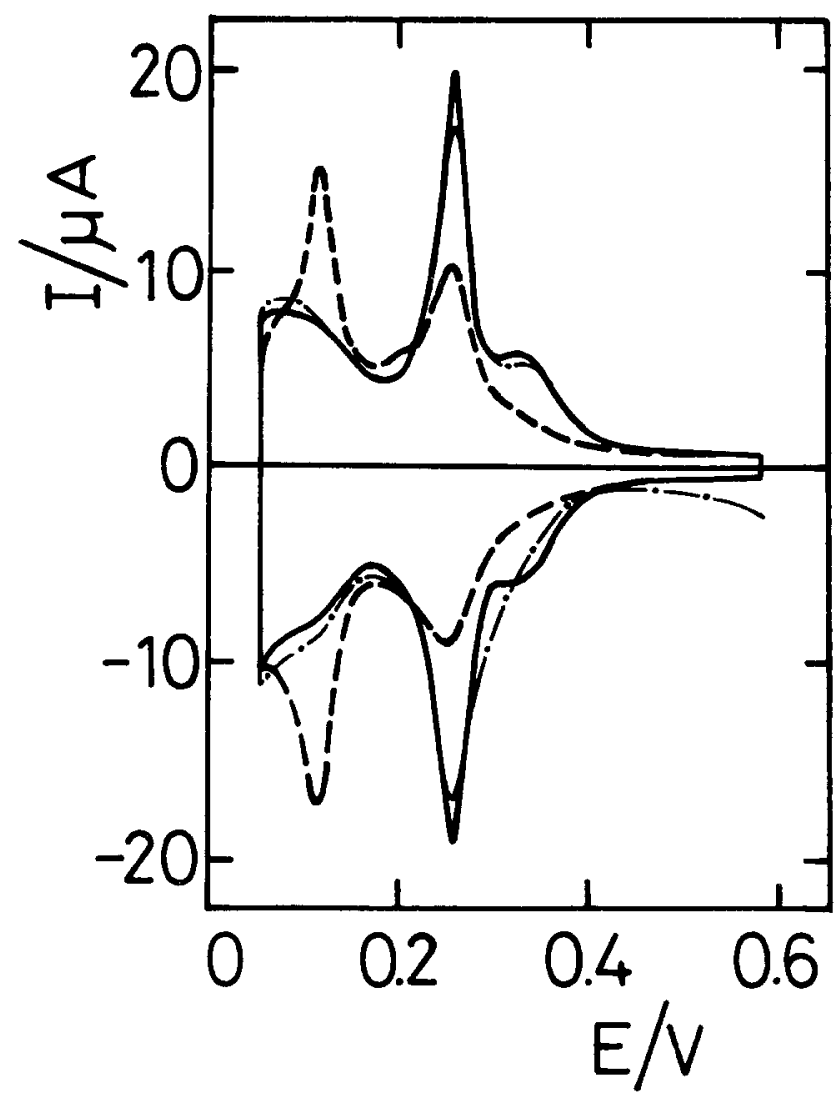

Fig. 7. Voltammograms run at $0.1 \mathrm{~V} / \mathrm{s}$ in $1 \mathrm{M} \mathrm{H}_{2} \mathrm{SO}_{4}$ at $25^{\circ} \mathrm{C}$ after $4 \mathrm{~h}$ RSWPS $\left(E_{1}=0.25 \mathrm{~V} ; E_{\mathrm{u}}=1.25 \mathrm{~V} ; f=4 \mathrm{kHz}\right)$. ( $(-)$ Voltammogram (third cycle) run between 0.05 and $0.60 \mathrm{~V} ;(-\ldots)$ voltammogram obtained after $10 \mathrm{~min}$ cycling between 0.05 and $1.50 \mathrm{~V} ;\left(-\right.$ - $^{-}$untreated electropolished polycrystalline platinum electrode.

surface is primarily determined by the values of $E_{1}, E_{\mathrm{u}}$, and $f$, whereas the actual shape of potential perturbations signal has a minor influence.

SEM patterns of the platinum (100) preferred oriented surface resulting after applying the RSWPS under the optimal conditions are depicted in Fig. 10, together with the pattern of the starting electropolished polycrystal-

Table I. Values of $h_{2} / h_{1}$ and $H(100)$ for different platinum electrodes

\begin{tabular}{|c|c|c|c|c|c|}
\hline Electrode & $\begin{array}{l}\text { Electrolyte } \\
\left(\mathrm{H}_{2} \mathrm{SO}_{4}\right)\end{array}$ & Potential perturbation & $h_{2} / h_{1}$ & $H(100)$ & Reference \\
\hline $\mathrm{Pt}(100) \operatorname{pos}(1)$ & $1.0 M$ & $\begin{array}{l}\text { 3rd cycle in the } \mathrm{H} \text {-adatom and dl } \\
\text { charging region at } 0.1 \mathrm{~V} / \mathrm{s}\end{array}$ & 2.2 & 2.1 & This work \\
\hline $\mathrm{Pt}(100)$ pos (2) & $1.0 M$ & $\begin{array}{l}\text { 3rd cycle in the } \mathrm{H} \text {-adatom and dl } \\
\text { charging region at } 0.1 \mathrm{~V} / \mathrm{s}\end{array}$ & 2.7 & 2.9 & This work \\
\hline $\operatorname{Pt}(100)$ pos $(3)$ & $1.0 M$ & $\begin{array}{l}\text { 10th cycle in the } \mathrm{H} \text {-adatom and d } \\
\text { charging region at } 0.1 \mathrm{~V} / \mathrm{s}\end{array}$ & 4.7 & 4.2 & (5) \\
\hline $\operatorname{Pt}(100)$ scs & $0.5 M$ & $\begin{array}{l}\text { 3rd cycle in the } \mathrm{H} \text {-adatom and dl } \\
\text { charging region at } 0.05 \mathrm{~V} / \mathrm{s}\end{array}$ & 3.4 & - & (9) \\
\hline $\operatorname{Pt}(100) \operatorname{ses}$ & $0.5 M$ & $\begin{array}{l}\text { A few cycles in the O-adatom re- } \\
\text { gion at } 0.05 \mathrm{~V} / \mathrm{s}\end{array}$ & 1.9 & - & $(9)$ \\
\hline $\operatorname{Pt}(100)$ ses & $0.5 M$ & $\begin{array}{l}\text { One cycle in the O-adatom region } \\
\text { at } 0.05 \mathrm{~V} / \mathrm{s}\end{array}$ & 2.4 & - & (11) \\
\hline $\operatorname{Pt}(100)$ scs & $1.0 M$ & $\begin{array}{l}\text { More than } 5 \text { cycles in the } \mathrm{O} \text {-ad- } \\
\text { atom region at } 0.01 \mathrm{~V} / \mathrm{s}\end{array}$ & 3.1 & - & (8) \\
\hline $\operatorname{Pt}(100)$ ses & $0.5 M$ & $\begin{array}{l}\text { One cycle in the } \mathrm{H} \text {-adatom and dl } \\
\text { charging region at } 0.05 \mathrm{~V} / \mathrm{s}\end{array}$ & 6.9 & - & (12) \\
\hline Pt(100) ses & $0.5 M$ & $\begin{array}{l}\text { One cycle in the O-adatom region } \\
\text { at } 0.05 \mathrm{~V} / \mathrm{s}\end{array}$ & 5.1 & - & $(12)$ \\
\hline $\operatorname{Pt}(100)$ ses & $0.5 M$ & $\begin{array}{l}6 \text { cycles in the } \mathrm{O} \text {-adatom region at } \\
0.05 \mathrm{~V} / \mathrm{s}\end{array}$ & 3.6 & - & (12) \\
\hline $\mathrm{Pt}(100)$ ses & $0.5 M$ & $\begin{array}{l}\text { Cycle in the } \mathrm{H} \text {-adatom and } \mathrm{dl} \\
\text { charging region at } 0.05 \mathrm{~V} / \mathrm{s}\end{array}$ & 5.4 & - & (13) \\
\hline $\operatorname{Pt}(100)$ ses & $0.005 M$ & $\begin{array}{l}\text { Less than } 15 \text { cycles in the } \mathrm{O} \text {-ad- } \\
\text { atom region, then second or } \\
\text { third cycle in } \mathrm{H} \text {-adatom and dl } \\
\text { charging region at } 0.05 \mathrm{~V} / \mathrm{s}\end{array}$ & 2.7 & - & (14) \\
\hline
\end{tabular}

pos: preferred oriented surface. scs: single crystal surface. (1) RSWPS $\left(E_{1}=0.25 \mathrm{~V} ; E_{\mathrm{u}}=1.25 \mathrm{~V} ; f=4 \mathrm{kHz} ; t=5 \mathrm{~min}\right)$. (2) RSWPS ( $E_{\mathrm{l}}=$ $\left.0.25 \mathrm{~V} ; E_{\mathrm{u}}=1.25 \mathrm{~V} ; f=4 \mathrm{kHz} ; t=4 \mathrm{~h}\right)$. (3) Repetitive triangular potential scanning $\left(E_{1}=0.002 \mathrm{~V} ; E_{\mathrm{u}}=1.50 \mathrm{~V} ; f=4.7 \mathrm{kHz} ; t=12 \mathrm{~h}\right)$. 


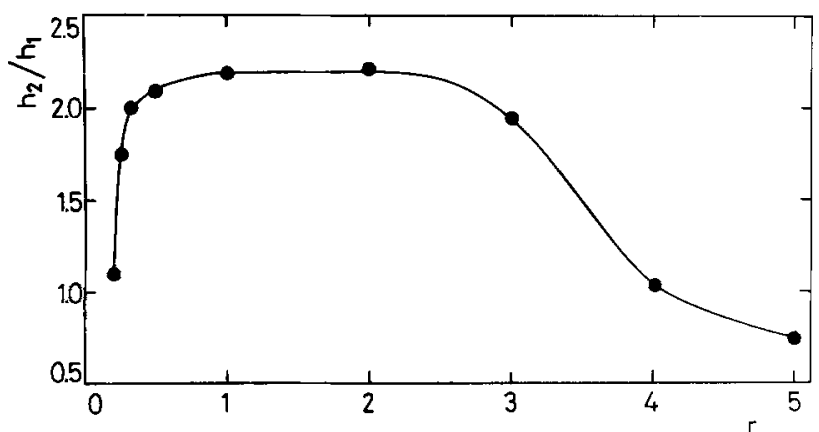

Fig. 8. Dependence of $h_{2} / h_{1}$ on $r$ at constant $f ; E_{1}=0.25 V ; E_{u}=$ $1.25 \mathrm{~V} ; f=4 \mathrm{kHz}, \mathrm{t}=5 \mathrm{~min}$.

line platinum electrode. The comparison of the different platinum surfaces shows that the RSWPS treatment develops a net faceting at each surface grain.

Development of the (111) preferred crystal orientation.-At constant $f$ and $t$, the useful ranges of $E_{1}$ and $E_{\text {u }}$ for producing surface structures with the (111) preferred orientation are narrower than those described in the section above, that is, $0.50 \mathrm{~V} \leq E_{1} \leq 0.70 \mathrm{~V}$ and $1.30 \mathrm{~V} \leq E_{\mathrm{u}}$ $\leq 1.40 \mathrm{~V}$. Thus, after applying the RSWPS with $E_{1}=0.70 \mathrm{~V}$, $E_{\mathrm{u}}=1.40 \mathrm{~V}, f=2 \mathrm{kHz}$, and $t=5 \mathrm{~min}$ to a polycrystalline platinum electrode, the voltammogram of the resulting surface run at $0.1 \mathrm{~V} / \mathrm{s}$ between 0.05 and $0.60 \mathrm{~V}$ (Fig. 11) approaches that of a platinum (111) single crystal surface after it has been cycled a few times through the O-electroadsorption region at a relatively low potential sweep rate, e.g., $0.1 \mathrm{~V} / \mathrm{s}(8-11,13,14,16,19,20)$ and is also similar to that directly resulting from a platinum (111) single crystal surface cleaned in UHV (argon and oxygen ionic bombardment at $750 \mathrm{eV}$ and $500^{\circ} \mathrm{C}$ ) and characterized by LEED and AES (21). After one potential cycle in the O-electroadsorption potential range, the voltammogram of the platinum (111) preferred oriented sur-

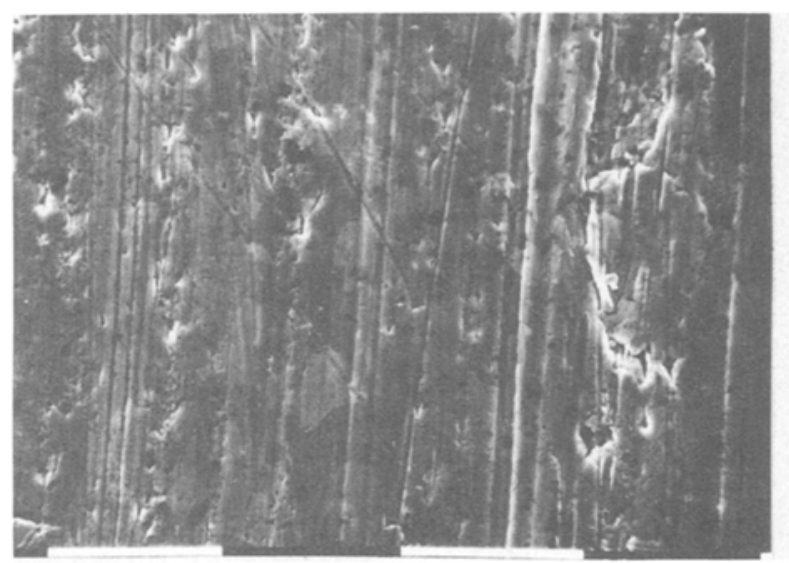

a

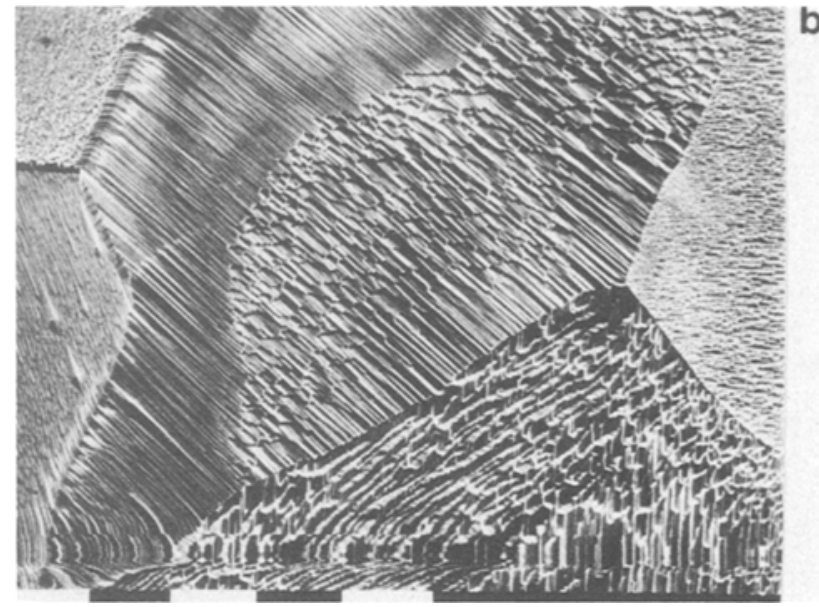

Fig. 10. SEM patterns (Scale $10 \mu \mathrm{m}$ ). (a) Initial electropolished polycrystalline platinum electrode; $(b, c)$ platinum surfaces after $4 \mathrm{~h}$ RSWPS $\left(E_{1}=0.25 \mathrm{~V}, E_{\mathrm{u}}=1.25 \mathrm{~V}, f=4 \mathrm{kHz}\right)$. 


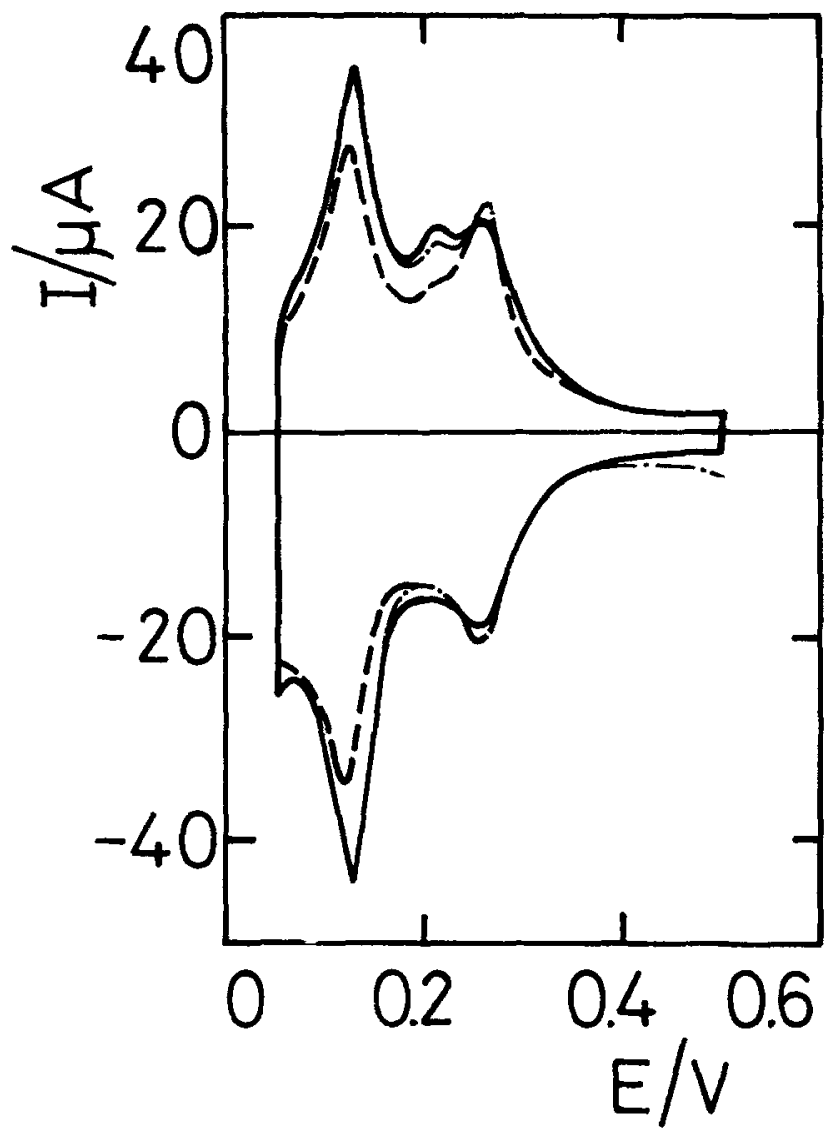

Fig. 11. Voltammograms run at $0.1 \mathrm{~V} / \mathrm{s}$ in $1 \mathrm{M} \mathrm{H}_{2} \mathrm{SO}_{4}$ at $25^{\circ} \mathrm{C}$ after 5 $\min \operatorname{RSWPS}\left(E_{1}=0.70 \mathrm{~V} ; E_{\mathrm{u}}=1.40 \mathrm{~V} ; f=2 \mathrm{kHz}\right)$. ( $(\longrightarrow)$ Voltammogram (third cycle) run between 0.05 and $0.60 \mathrm{~V} ;(-\ldots)$ voltammogram obtained after $10 \mathrm{~min}$ cycling between 0.05 and $1.50 \mathrm{~V} ;(-)_{1}$ untreated electropolished polycrystalline platinum electrode.

ferent $h_{1} / h_{2} v s$. $t$ plots are obtained depending on whether the repetitive triangular potential sweep (RTPS) at 0.1 $\mathrm{V} / \mathrm{s}$ is restricted to the $0.05-0.60 \mathrm{~V}$ range, or is extended up to the O-electroadsorption potential range (Fig. 13). In the former case, the $h_{1} / h_{2}$ ratio.increases initially with $t$, goes through a maximum at about $15 \mathrm{~s}$, and then decreases to a time independent value. The voltammetric sweep up to $1.50 \mathrm{~V}$ decreases the $h_{1} / h_{2}$ ratio in the direction of the voltammetric response of the initial polycrystalline platinum electrode, according to the duration of the RTPS. In this case, the greatest influence of the RTPS at low potential sweep rate on the $h_{1} / h_{2}$ ratio is noticed for the resulting surfaces after RSWPS treatments

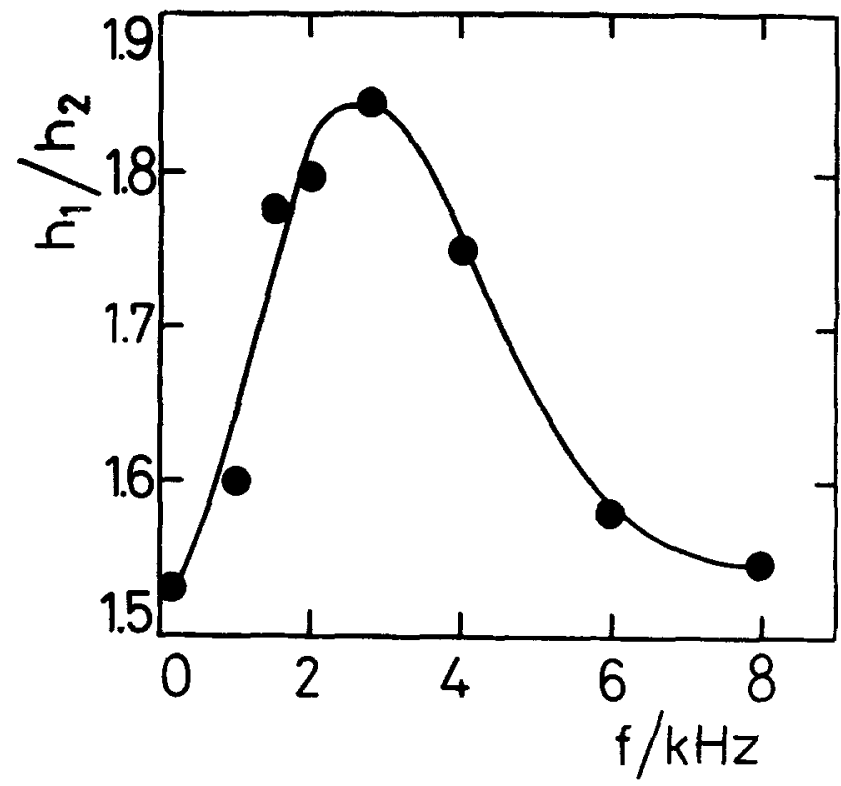

Fig. 12. Dependence of $h_{1} / h_{2}$ on $f ; E_{1}=0.70 \mathrm{~V} ; E_{\mathrm{u}}=1.40 \mathrm{~V} ; t=5$ $\min$.

of small duration. This suggests that the shorter the duration of the RSWPS, the greater the unstability of the modified platinum surface. On the other hand, those electrodes prepared with a RSWPS treatment lasting more than $3 \mathrm{~min}$, still exhibit a relatively large $h_{1} / h_{2}$ ratio, and a good stability to the RTPS at $0.1 \mathrm{~V} / \mathrm{s}$ covering the O-electroadsorption potential range. In this respect, the stability of the platinum (111) preferred oriented surface electrodes appears greater than that reported for platinum (111) single crystal electrodes $(9-11,13,16,20,21)$.

The amount of soluble ionic platinum found after the RPWS treatment for the optimal conditions for developing the (111) preferred orientation is slightly greater (ca. four times) than that reported in the section above (17).

The development of the (111) preferred orientation depends also on the symmetry of the RSWPS. Thus, for the optimal conditions, the maximum $h_{1} / h_{2}$ ratio is found for $r$ values between 0.5 and 2.0 (Fig. 14). Again, the greatest voltammetric change is associated with the symmetric RSWPS signal.

SEM patterns of platinum (111) preferred oriented surfaces resulting after applying the RSWPS treatment under the optimal conditions are depicted in Fig. 15. In this case, a characteristic faceting is also developed, although the corresponding pictures at the largest magnifications are more diffuse than those shown for platinum (100) preferred oriented surfaces probably because of the

Table II. Values of $h_{1} / h_{2}$ for different platinum electrodes

\begin{tabular}{|c|c|c|c|c|}
\hline Electrode & Electrolyte & Potential perturbation & $h_{1} / h_{2}$ & Reference \\
\hline $\operatorname{Pt}(111) \operatorname{pos}(1)$ & $1.0 \mathrm{M} \mathrm{H}_{2} \mathrm{SO}_{4}$ & $\begin{array}{l}\text { 3rd cycle in the } \mathrm{H} \text {-adatom and } \mathrm{dl} \\
\text { charging region at } 0.1 \mathrm{~V} / \mathrm{s}\end{array}$ & 2.0 & This work \\
\hline $\operatorname{Pt}(111) \operatorname{pos}(2)$ & $1.0 \mathrm{M} \mathrm{H}_{2} \mathrm{SO}_{4}$ & $\begin{array}{l}\text { 3rd cycle in the } \mathrm{H} \text {-adatom and } \mathrm{dl} \\
\text { charging region at } 0.1 \mathrm{~V} / \mathrm{s}\end{array}$ & 1.8 & This work \\
\hline $\operatorname{Pt}(111)$ pos $(3)$ & $1.0 \mathrm{M} \mathrm{H}_{2} \mathrm{SO}_{4}$ & $\begin{array}{l}\text { 3rd cycle in the H-adatom and } d l \\
\text { charging region at } 0.1 \mathrm{~V} / \mathrm{s}\end{array}$ & 2.0 & $(5)$ \\
\hline $\operatorname{Pt}(111) \operatorname{ses}$ & $0.5 \mathrm{M} \mathrm{H}_{2} \mathrm{SO}_{*}$ & $\begin{array}{l}\text { One cycle in the } 0 \text {-adatom region } \\
\text { at } 0.05 \mathrm{~V} / \mathrm{s}\end{array}$ & 1.4 & (20) \\
\hline $\operatorname{Pt}(111) \operatorname{ses}(4)$ & $1.0 \mathrm{M} \mathrm{H}_{2} \mathrm{SO}_{4}$ & $\begin{array}{l}\text { One cycle between } 0.05 \text { and } 1.55 \mathrm{~V} \\
\text { at } 0.1 \text { V/s after Ar- and O-ionic } \\
\text { bombardment }\end{array}$ & 1.4 & (21) \\
\hline $\operatorname{Pt}(111) \operatorname{scs}(5)$ & $1.0 \mathrm{M} \mathrm{H}_{2} \mathrm{SO}_{z}$ & $\begin{array}{l}8 \text { cycles in the O-adatom region at } \\
0.1 \mathrm{~V} / \mathrm{s}\end{array}$ & 3.0 & (21) \\
\hline Pt(111) ses & $0.5 M \mathrm{H}_{2} \mathrm{SO}_{4}$ & $\begin{array}{l}\text { One cycle in the } O \text {-adatom region } \\
\text { at } 0.05 \mathrm{~V} / \mathrm{s}\end{array}$ & 3.0 & (11) \\
\hline $\operatorname{Pt}(111) \mathrm{scs}$ & $1.0 \mathrm{M} \mathrm{H}_{2} \mathrm{SO}_{4}$ & $\begin{array}{l}\text { More than } 5 \text { cycles in the } \mathrm{O} \text {-ad- } \\
\text { atom region at } 0.01 \mathrm{~V} / \mathrm{s}\end{array}$ & 2.8 & (8) \\
\hline Pt(111) ses & $0.1 M \mathrm{HClO}_{4}$ & $\begin{array}{l}10 \mathrm{cycles} \text { in the } \mathrm{O} \text {-adatom region } \\
\text { at } 0.1 \mathrm{~V} / \mathrm{s}\end{array}$ & 2.9 & (10) \\
\hline
\end{tabular}

pos: preferred oriented surface. ses: single crystal surface. (1) RSWPS $\left(E_{1}=0.70 \mathrm{~V} ; E_{\mathrm{u}}=1.40 \mathrm{~V} ; f=2.8 \mathrm{kHz} ; t=40 \mathrm{~s}\right)$. (2) RSWPS ( $E_{1}=$ $\left.0.70 \mathrm{~V} ; E_{\mathrm{u}}=1.40 \mathrm{~V} ; f=2.8 \mathrm{kHz} ; t=5 \mathrm{~min}\right)$. (3) Repetitive triangular potential scanning $\left(E_{1}=0.42 \mathrm{~V} ; E_{\mathrm{u}}=1.10 \mathrm{~V} ; f=7.4 \mathrm{kHz} ; t=12 \mathrm{~h}\right)$. (4) "Initial state." (5) "Standard state." 


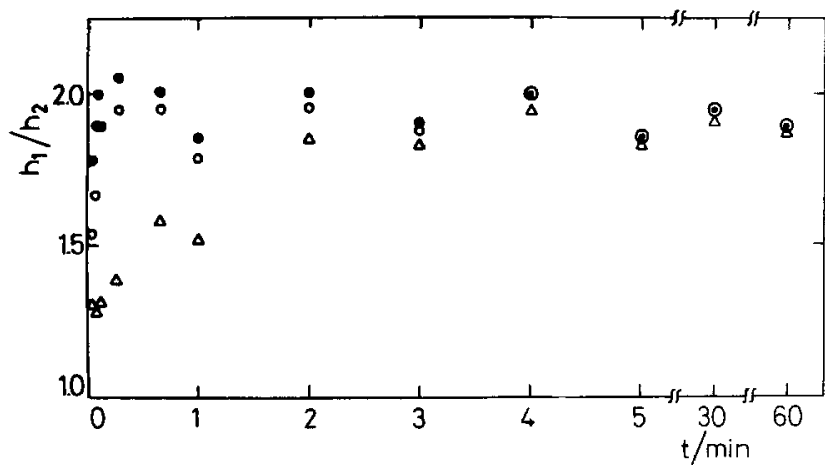

Fig. 13. Dependence of $h_{1} / h_{2}$ on $t ; E_{1}=0.70 V_{i} E_{u}=1.40 \mathrm{~V} ; f=2.8$ $\mathrm{kHz}$. (O) Data derived from voltammograms (third cycle) run at $0.1 \mathrm{~V} / \mathrm{s}$ between 0.05 and $0.60 \mathrm{~V} ;(O)$ Data derived from voltammograms (first cycle) run at $0.1 \mathrm{~V} / \mathrm{s}$ between 0.05 and 1.50V; $(\Delta)$ Data derived from voltammograms obtained at $0.1 \mathrm{~V} / \mathrm{s}$ after $10 \mathrm{~min}$ cycling between 0.05 and $1.50 \mathrm{~V}$.

shorter duration time of the RSWPS. The latter was usually selected in the region where the $h_{1} / h_{2}$ ratio attains a time independent value (Fig. 14).

\section{Discussion}

The preferred oriented platinum surfaces can be obtained by applying fast periodic potential perturbations to polycrystalline platinum electrodes between potential limits associated with the underpotential decomposition of water (1-5). Present results establish that for preset $E_{1}$ and $E_{u}$, the development of preferred orientations depends on the frequency of the potential perturbation independently of the actual shape of the periodic potential perturbation. This means that only the first harmonics

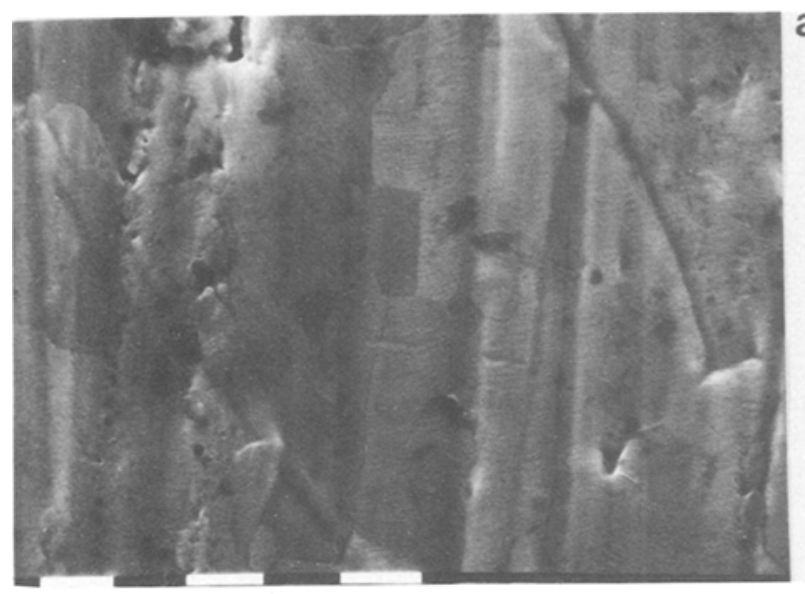

a

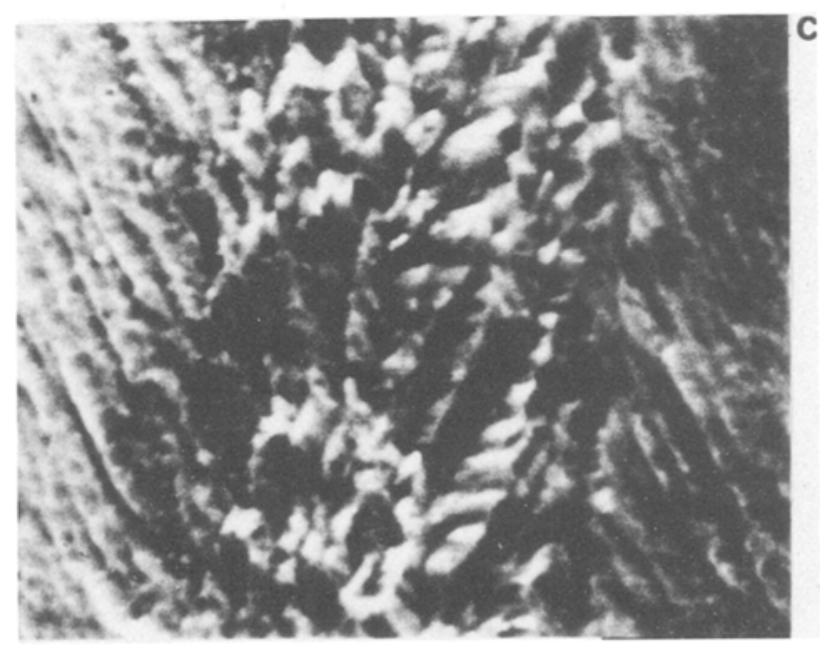

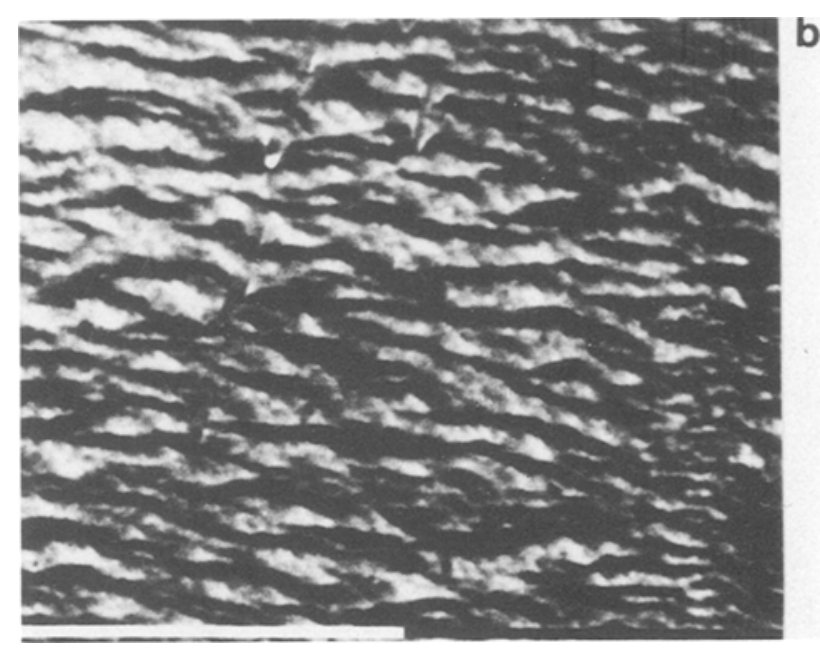

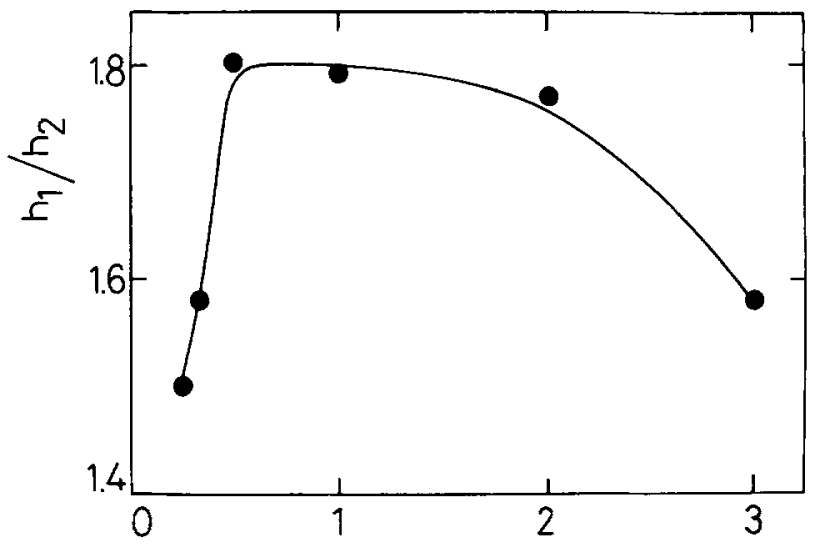

Fig. 14. Dependence of $h_{1} / h_{2}$ on $r$ at a constant $f_{i} E_{1}=0.70 \mathrm{~V} ; E_{\mathrm{u}}=$ $1.40 \mathrm{~V} ; f=2.0 \mathrm{kHz} ; t=5 \mathrm{~min}$.

are mainly responsible for promoting the preferred orientation (22). Despite this conclusion, data obtained with the RSWPS appears more reliable for defining the actual potential limits associated with the phenomenon. The overall process involves at least two consortial stages, one which promotes the atom rearrangement through the occurrence of surface processes, and another one which assists the penetration in depth of the atom rearrangement.

The first stage is directly related to the characteristics of the fast periodic potential perturbation. Thus, for constant $E_{1}, f$, and $t$, there is a lower threshold $E_{\mathrm{u}}$ value located at ca. $1.10 \mathrm{~V}$ to develop a platinum (100) preferred oriented surface. This means that $E_{\mathrm{u}}$ should attain the O-electroadsorption potential range for weakening the $\mathrm{Pt}-\mathrm{Pt}$ bonds for further producing the platinum surface

Fig. 15. SEM patterns [Scales $1 \mu \mathrm{m}$ (a) and $10 \mu \mathrm{m}$ (b, c). (a) Initial electropolished polycrystalline platinum electrode; (b, c) platinum surfaces after $5 \min \operatorname{RSWPS}\left(E_{1}=0.70 \mathrm{~V} ; E_{\mathrm{u}}=1.40 \mathrm{~V} ; f=2.8 \mathrm{kHz}\right)$. 
atom rearrangement. However, at $E_{u}$ values higher than $1.40-1.50 \mathrm{~V}$, that is, at potentials sufficiently positive to form irreversible $O$-surface species $(23,24)$, the efficiency for developing the preferred orientation declines significantly, indicating that the strong O-electroadsorption hinders the surface restructuring process. Likewise, to develop the (111) preferred orientation the $E_{\mathrm{u}}$ value should also be located in the O-electroadsorption potential range, although, in this case, the useful $E_{\mathrm{u}}$ range is restricted to $1.30-1.40 \mathrm{~V}$. Furthermore, for the development of either the (100) or the (111) preferred orientation the $E_{1}$ values should lie in the potential range where $\mathrm{O}-\mathrm{Pt}$ bonds are broken. Therefore, very active electrosorbed oxygen containing species promoting the disruption and the rearrangement of the surface structure, play a fundamental role in the development of preferred orientations. This is consistent with the fact that there is a frequency threshold for producing preferred oriented platinum surfaces, which is ca. $0.5 \mathrm{kHz}$. The reciprocal of this figure was associated with the half-life time of adsorbed $\mathrm{OH}$ species on platinum produced in the early stages of underpotential electro-oxidation of water $(25,26)$. Thus, the anodic processes which initiate the surface rearrangement are

$$
\begin{gathered}
\mathrm{H}_{2} \mathrm{O}+\mathrm{Pt}=[\mathrm{Pt}(\mathrm{OH})]^{*}+\mathrm{H}^{+}+e \\
{[\mathrm{Pt}(\mathrm{OH})]^{*}=[\mathrm{Pt}(\mathrm{O})]^{*}+\mathrm{H}^{+}+e}
\end{gathered}
$$

Reactions [2a] and [2b] involve two successive reactions leading to the formation of adsorbed nonstabilized O-containing species. These reactions should occur preferentially at those sites which involve the smallest overvoltage, that is, at the most reactive sites of the polycrystalline surface (steps, kinks, etc). The surface rearrangement occurring during the O-electrodesorption half-cycle is associated with reactions such as

$$
\begin{gathered}
{[\mathrm{Pt}(\mathrm{O})]^{*}+\mathrm{H}^{+}+e=[\mathrm{Pt}(\mathrm{OH})]^{*}} \\
{[\mathrm{Pt}(\mathrm{OH})]^{*}+\mathrm{H}^{+}+e=\mathrm{Pt}^{*}+\mathrm{H}_{2} \mathrm{O}}
\end{gathered}
$$

where the freshly formed $\mathrm{Pt}$ * atom occupies, in principle, a new equilibrium position in the metal lattice, according to

$$
\mathrm{Pt}^{*} \rightarrow \mathrm{Pt}(\text { lattice })
$$

The reaccommodation reaction [4] depends on the number of degrees of freedom of $\mathrm{Pt}$ *atoms on the metal surface. Hence, the first layers of metal atoms under the fast periodic potential perturbation behave as a dynamic surface structure where the metal atoms move on the electrode surface, from initial metastable positions at the polycrystalline metal towards a certain equilibrium configuration. Furthermore, the presence of $\mathrm{H}$-adatoms interacting with the metal lattice promotes the formation of the lower dense metal surface structure. This is the case for developing the (100) preferred orientation which requires an $E_{1}$ value located in the $\mathrm{H}$-adatom electroadsorption/electrodesorption potential range. Conversely, surface structures where the (111) preferred orientation prevails imply no H-electroadsorption/ electrodesorption during the RSWPS.

The dependence of the efficiency of preferred oriented surface development on both the frequency and the symmetry of the RSWPS indicates that either aging reactions yielding irreversible electroadsorbed O-containing species or strong ion-metal and solvent-metal interactions, hinder the development of surface structures with a preferred orientation. Therefore, the optimal frequency and symmetry conditions of the RSWPS result from a compromise between the rates of reactions [2a] and [2b] coupled to the aging reaction of the O-electroadsorbed species and the rates of reactions [3a], [3b], and [4] coupled to the different adsorption processes on bare platinum.

The second stage of the preferred oriented surface development process, which occurs in parallel with the first one already discussed, concerns the penetration in depth of the rearrangement of metal atoms. The occurrence of this stage is consistent with recent results obtained with polycrystalline platinum electrodes subjected to fast potential perturbations (17) which show that the amount of dissolved platinum per cycle under the optimal conditions for developing preferred oriented surfaces is $10^{2}-10^{3}$ times lower than that produced per cycle under potential cycling at $0.04 \mathrm{~V} / \mathrm{s}$ between 0.40 and $1,50 \mathrm{~V}$ (18). This suggests that a local electrodissolution and electrodeposition of platinum contribute to the penetration of the rearrangement effect. The mechanism of the second stage is similar, in principle, to that earlier proposed by other authors to explain the roughening of platinum electrodes by cyclic potential programs $(27,28)$.

In this respect it is interesting to notice that working under a constant potential amplitude and time, there is a development of surface roughness together with the preferred orientation effect as has been reported earlier for fast repetitive triangular potential cycling (3). The development of roughness is particularly remarkable for (111) preferred oriented surfaces as, in this case, the $E_{\mathrm{u}}$ value should be more positive than that required for developing the (100) preferred orientation. The relative contributions of roughening and preferred orientation effects depend on the frequency of the periodic potential perturbation. Thus, at $f$ lower than $2 \mathrm{kHz}$, the former occurs simultaneously with the latter, but when $f$ exceeds $2 \mathrm{kHz}$, then there is practically no increase in surface roughness. The optimal $f$ range for developing the platinum (111) preferred orientation is comprised between 2 and $3.5 \mathrm{kHz}$, but for $f$ greater than $3.5 \mathrm{kHz}$ the preferred orientation effect decreases again. On the other hand, for the optimal $E_{1}$ and $E_{\mathrm{u}}$ values to develop the (100) preferred orientation, an appreciable roughness is only produced at $f$ values lower than $0.05 \mathrm{kHz}$. The greatest efficiency for developing the preferred orientation effect is accomplished in the $2-6 \mathrm{kHz}$ range with a negligible increase in the electrode roughness. Nevertheless, at $f$ values larger than $8 \mathrm{kHz}$, as the RSWPS is appreciably distorted, the preferred orientation effect decreases. In this case, a decrease in the surface heterogeneity is observed as it is reflected through the sharpening of the main $\mathrm{H}$-adatom electroadsorption/electrodesorption current peaks and the disappearance of the anodic intermediate current peak in the voltammogram at $0.1 \mathrm{~V} / \mathrm{s}$.

As was pointed out in previous work $(5,15)$, the effect of fast periodic potential perturbations on the surface modification resembles those induced in single crystals by either bombardment with high energy particles $(21$, $29)$ or thermal treatment $(21,30,31)$ or O-adsorption from the gas-phase $(30,32)$ yielding restructuring and eventually faceting. In these cases, the stabilization process of the perturbed surface implies an energy dissipation effect involving short and large range atom rearrangements. The former is associated principally with filling of holes in the metal structure induced by the mobility of the metastable atoms produced by the perturbation and to mutual annihilation of dislocations. The large range energy dissipation effect is associated with the faceting of the surface and implies a transfer of momentum from the mobile atom to the metal atom network $(15,33)$. The metastable metal atoms stabilize in the metal lattice when its translation energy turns into the vibrational lattice energy corresponding to the equilibrium metal structure.

\section{Acknowledgment}

INIFTA is a research institute jointly established by the Universidad Nacional de La Plata, the Consejo Nacional de Investigaciones Cientificas y Técnicas, and the Comisión de Investigaciones Cientificas (Provincia de Buenos Aires). This work is partially supported by the Regional Program for the Scientific and Technological Development of the Organization of American States. The authors acknowledge the Instituto Nacional de Tecnologia Industrial (INTI) for the facilities for obtaining the SEM patterns. 
Manuscript submitted Sept. 9, 1985; revised manuscript received Dec. 8,1986 . This was Paper 654 presented at the Toronto, Ontario, Canada, Meeting of the Society, May 12-17, 1985

Instituto de Investigaciones Fisicoquimicas Teoricas y Aplicadas assisted in meeting the publication costs of this article.

\section{REFERENCES}

1. J. C. Canullo, W. E. Triaca and A. J Arvia, J Electroanal. Chem. Interfacial Electrochem., 175, 337 (1984).

2. R. M. Cervin̄o, W. E. Triaca, and A. J. Arvia, ibid., 132, 266 (1985).

3. R. M. Cervin̄o, W. E. Triaca, and A. J. Arvia, ibid., 182, 51 (1985).

4. R. M. Cervin̄o, A. J. Arvia, and W. Vielstich, Surf. Sci., 154, 623 (1985).

5. R. M. Cervin̄o, W. E. Triaca, and A. J. Arvia, Electrochim. Acta, 10, 1323 (1985)

6. F. G. Will, This Journal, 112, 451 (1965)

7. E. Yeager, W. E. O'Grady, M. Y. C. Woo, and P. Hagans, ibid., 125, 348 (1978).

8. A. T. Hubbard, R. M. Isnikawa, and J. Katekaru, J. Electroanal. Chem. Interfacial Electrochem., 86, 271 (1978).

9. K. Yamamoto, D. M. Kolb, R. Kötz, and G. Lehmpfuhl, ibid., 36, 233 (1979).

10. P. N. Ross, Jr., This Journal, 126, 67 (1979).

11. P. N. Ross, Jr., Surf. Sci., 102, 463 (1981).

12. J. Clavilier, R. Durand, G. Guinet, and R. Faure, J. Electroanal. Chem. Interfacial Electrochem., 127, 281 (1981).

13. C. L. Scortichini and C. N. Reilley, ibid., 139, 233, 247 (1982).

14. F. E. Woodward, C. L. Scortichini, and C. N. Reilley, ibid., 151, 109 (1983).

15. A. C. Chialvo, W. E. Triaca, and A. J. Arvia, Anal. Asoc. Quim. Argen., 73(1), 23 (1985).
16. F. T. Wagner and P. N. Ross, Jr., J. Electroanal. Chem. Interfacial Electrochem., 150, 141 (1983).

17. L. Perdriel, W. E. Triaca, and A. J. Arvia, ibid., In press.

18. D. A. J. Rand and R. Woods, ibid., 35, 209 (1972).

19. P. N. Ross, Jr., ibid., 76, 139 (1977).

20. J. Clavilier, R. Faure, G. Guinet, and R. Durand, ibid., 10\%, 205 (1980).

21. D. Aberdam, C. Corotte, D. Dufayard, R. Durand, R. Faure, and G. Guinet, in "Proceedings of 4th International Conference on Solid Surfaces," Vol. 1, P.A. Degras and M. Costa, Editors, p. 622, Supplement to "Le Vide, les Couches Minces," N 201, Cannes, France (1980).

22. E. Custidiano and A. J. Arvia, In preparation.

23. N. R. de Tacconi, A. J. Calandra, and A. J. Arvia, J Electroanal. Chem. Interfacial Electrochem., 5\%, 267 (1974).

24. J. O. Zerbino, N. R. de Tacconi, A. J. Calandra, and A. J. Arvia, This Journal, 124, 475 (1977).

25. A. C. Chialvo, W. E. Triaca, and A. J. Arvia, $J$. Electroanal. Chem. Interfacial Electrochem., 146, 93 (1983).

26. A. C. Chialvo, W. E. Triaca, and A. J. Arvia, ibid., 171, 303 (1984)

27. D. C. Johnson, D. T. Napp, and S. Bruckenstein, Electrochim. Acta, 15, 1493 (1970)

28. D. F. Untereker and S. Bruckenstein, This Journal, 121, 360 (1974).

29. G. K. Wehner, Phys. Rev., 102, 690 (1956)

30. S. Motoo and N. Furuya, J. Electroanal. Chem. Interfacial Electrochem., 172, 339 (1984).

31. A. Wieckowski, T. Solomon, B. C. Schardt, S. D. Rosasco, J. L. Stickney, and A. T. Hubbard, in " 35 th Meeting of International Society of Electrochemistry," p. 438, Berkeley, CA (1984).

32. J. W. May, Ind. Eng. Chem., 57, 19 (1965).

33. M. Kaminsky, "Atomic and Ionic Impact Phenomena on Metal Surfaces," Springer-Verlag, Berlin-Heidelberg (1965).

\title{
The Effect of an Impinging Fluid Jet on Mass Transfer and Current Distribution in a Circular Through-Hole
}

\author{
Richard C. Alkire* and Jeh-Beck Ju** \\ Department of Chemical Engineering, University of Illinois at Urbana-Champaign, Urbana, Illinois 61801
}

\section{ABSTRACT}

The effect of a single circular impinging fluid jet on hydrodynamic flow and mass transfer in a single through-hole centered at the stagnation point was investigated. Both submerged and unsubmerged jets were studied. Sectioned electrodes were used for direct experimental measurement of local rates of mass transfer and of hydrodynamic shear stress within in dividual through-holes. The ferricyanide system was used to obtain convective mass transfer rates upon controlled variation of jet Reynolds number, nozzle-to-workpiece distance, through-hole diameter, and aspect ratio. Data were used to establish mass-transfer correlations for both submerged and unsubmerged systems. It was found that the fluid flow in the through-hole corresponded to the hydrodynamic entrance region. A mathematical model of the current and potential distribution was used to identify dimensionless conditions for achieving uniform deposits and for insuring adequate convection rates.

In applications where electrodeposits of uniform thickness are required over a surface of complex geometry, there usually exists an upper limit of plating rate above which the desired uniformity is not obtained. Deposit uniformity depends upon the current and potential field distribution within the cell. For high speed plating, there is usually a minimum flow rate needed to avoid powdery of "burned" deposits. Convective mass transport phenomena determine the cathodic limiting current density, or maximum deposition rate. Mathematical models based on mass transfer and potential field principles thus find use in predicting and scaling operating conditions to achieve both uniform and high speed performance. In the present study, the effect of impinging jet flow on the current and potential distribution in a single through-hole was investigated (1).

*Electrochemical Society Life Member.

**Electrochemical Society Active Member
Kessler and Alkire $(2,3)$ investigated electrodeposition in through-holes and developed procedures for estimating flow velocities needed for adequate agitation during deposition. Their results were based on an idealized configuration of mass transfer in a tubular electrode, the fundamentals of which had previously been investigated by Alkire and Mirarefi $(4,5)$. More recently, Haak and coworkers (6) investigated the effect of air sparging and sinusoidal board motion on mass transfer in the throughholes; they also suggested various novel agitation systems for improving the mass transport including the pumping of electrolyte through nozzles directed at the board. Sonin (7) investigated the configuration consisting of multiple unsubmerged jets impinging on a circuit board which hung vertically during deposition.

Impinging jet systems are widely used to enhance rates of heat and mass transfer in applications such as annealing of metal and plastics, cooling of turbine 